\title{
ANATOMÍA DE DICOTILEDÓNEAS: TALLOS DE HIERBAS TERRESTRES MEDICINALES RIOPLATENSES (BUENOS AIRES, ARGENTINA)
}

\author{
ANA M. ARAMBARRI ${ }^{1,3 *}$, MARÍA C. NOVOA ${ }^{1,3}$, MARCELO P. HERNÁNDEZ $Z^{2,3}$, MARTA N. COLARES ${ }^{1,3}$ \& \\ VANESA G. PERROTTA ${ }^{1,3}$
}

\begin{abstract}
Summary: Arambarri, A. M., M. C. Novoa, M. P. Hernández, M. N. Colares \& V. G. Perrotta. 2013. Anatomy of the Dicotyledons: stems of land herbs used as medicinal in the Río de La Plata area (Buenos Aires, Argentina). Bonplandia 22(2): 107-130. 2013.

Anatomy of the stems of 37 land herbs belonging to 19 families was studied. These organs are used in folk medicine in the Río de La Plata area. The objective was to get diagnostic characters to elaborate a key to distinguish the taxa from whole or fragmented stem samples. Fresh material and herbaria specimens were analyzed. Conventional histological methods and histochemical analysis to recognize starch, mucilage, lipophilic and phenolic substances were performed. The main differential traits were found in: stem outline in transection; presence and trichome types; stomata position respect to epidermal cells; presence of hypodermis or cortical fiber rings; eustele with two vascular bundles cycles; a conspicuous endodermis; presence of different crystal types and secretory structures; presence of lipophilic, mucilage and starch compounds. On the basis of the diagnostic morpho-histological characters a key was elaborated.
\end{abstract}

Key words: Cladode, medicinal plants, stem structure.

Resumen: Arambarri, A. M., M. C. Novoa, M. P. Hernández, M. N. Colares \& V. G. Perrotta. 2013. Anatomía de Dicotiledóneas: tallos de hierbas terrestres medicinales rioplatenses (Buenos Aires, Argentina). Bonplandia 22(2): 107-130. 2013.

Se estudió la anatomía de los tallos de 37 hierbas terrestres pertenecientes a 19 familias usadas en la medicina popular de la región rioplatense. El objetivo fue elaborar una clave dicotómica para la determinación de los taxones a partir de los caracteres morfo-histológicos de los tallos, ya sea que este material se encuentre al estado entero o fragmentado. Se estudiaron tallos frescos y de ejemplares de herbario, mediante técnicas histológicas convencionales. Se realizó análisis histoquímico para la identificación de almidón, mucílagos, sustancias lipídicas y fenólicas. Entre los caracteres diagnóstico hallados se destacan: contorno de la sección transversal del tallo; presencia y los tipos de tricomas; posición de los estomas con respecto al nivel de las restantes células epidérmicas; presencia de hipodermis, de anillos fibrosos en la corteza y de dos ciclos vasculares en la eustela; presencia de endodermis conspicua; diferentes tipos de cristales y estructuras secretoras internas, con sustancias lipófilas, mucílagos y la presencia de almidón. Los caracteres morfo-histológicos de los tallos permitieron elaborar una clave de diferenciación.

Palabras clave: Cladodios, plantas medicinales, estructura del tallo.

\footnotetext{
${ }^{1}$ Docentes-Investigadores de Morfología Vegetal; ${ }^{2}$ de Sistemática Vegetal; ${ }^{3}$ del Laboratorio de Morfología Comparada de Espermatofitas (LAMCE), Facultad de Ciencias Agrarias y Forestales, UNLP, 60 y 119, C.C. 31, 1900 La Plata, Argentina.

* Autor para correspondencia: Tel. +54-221-423-6758, int. 461; Fax: +54-221-425-2346. E-mail: anaramba@yahoo. com.ar; botgral@agro.unlp.edu.ar
} 


\section{Introducción}

Dentro de la Provincia Biogeográfica Pampeana con el aporte de las Provincias del Espinal y Paranaense se ubica la región rioplatense. Esta es una extensa área que se inicia en Diamante (Entre Ríos) y se extiende hasta la desembocadura del Río de La Plata. Dentro de esta área las especies analizadas en el presente estudio habitan el sector inferior del Delta del Paraná, isla Martín García y ribera rioplatense hasta Punta Lara en la provincia de Buenos Aires (Lahitte \& al., 1997). Existen numerosos trabajos desde el punto de vista florístico y sistemático de las plantas de esta zona (e.g. Hauman, 1925; Cabrera \& Dawson, 1944; Cabrera, 1949; Burkart, 1957; Cabrera \& Zardini, 1978) y del uso popular de las especies (Lahitte \& Hurrell, 1996; Lahitte \& al., 1997, 1998; Pochettino \& al., 1997; Hernández \& al., 2009, 2010, 2013; Hurrell \& al., 2011a, 2011b), así como sus propiedades medicinales (Hieronymus, 1882; Domínguez, 1928; Martínez Crovetto, 1964, 1981; Toursarkissian, 1980; Lahitte \& Hurrell, 1996; Lahitte \& al., 1998; Chifa \& Ricciardi, 2001; Carrizo \& al., 2002, 2005; Alonso \& Desmarchelier, 2005; Barboza \& al., 2006; Sawchuk Kobalchuk, 2006) y también estudios sobre anatomía de algunas de las especies aquí tratadas (e.g., Ancibor, 1980; Cosa 1991a, 1991b; Colares \& al., 1999; Barboza \& al. 2001; Liscovsky \& al., 2002; Bonzani \& al. 2003; Monti \& al., 2003; Duarte \& Debur, 2004; Apóstolo 2005; Liscovsky \& Cosa, 2005). Sin embargo, no se han realizado estudios comparativos de los órganos vegetativos de los taxones usados en la medicina folclórica de la región. En continuidad con el trabajo previo (Novoa $\&$ al., 2012) donde se presentó una clave basada en la anatomía comparada de los tallos aéreos y rizomas de Monocotiledóneas terrestres, en esta segunda parte, el objetivo es analizar los caracteres morfo-histológicos de los tallos de 37 especies de hierbas terrestres de Dicotiledóneas usados en la medicina popular de la región y, elaborar una clave dicotómica de diferenciación de los taxones estudiados. La profundización del conocimiento en este aspecto permitirá contar con un patrón para el adecuado control de calidad botánica.

\section{Materiales y Métodos}

Se utilizó material fresco conservado en FAA y de herbario. Parte del material coleccionado y determinado por los autores, se encuentra depositado en el herbario de la Facultad de Agronomía de La Plata (LPAG). Se estudiaron también tallos de ejemplares de los herbarios LP y SI (abreviaturas de acuerdo con Thiers, 2011). Los materiales analizados son de Argentina, en su mayoría recolectados en la provincia de Buenos Aires, pero también se han analizado materiales procedentes de las provincias de Entre Ríos y Santa Fe, como se indica en las siguientes referencias: AMARANTHACEAE: Alternanthera pungens Kunth, Buenos Aires: Ciudad Autónoma, V-2012, Auguet s.n. (LPAG). Santa Fe: Dep. Nueve de Julio, Tostado, 1-II-1936, Job 1124 (LP). ASTERACEAE: Achyrocline satureoides (Lam.) DC., Buenos Aires: Pdo. La Plata, Isla Martín García, 28-III-1997, Hurrell 3543 (LP). Acmella decumbens (Sm.) R. K. Jansen, Buenos Aires: Pdo. Berisso, Berisso, 8-X-2001, Torres \& Simon 512 (LP); Pdo. Ensenada, Punta Lara, 23-XI2002, Torres \& De Gregorio 1028 (LP). Ambrosia tenuifolia Spreng., Buenos Aires: Pdo. Ensenada, Isla Santiago, 14-III-2012, Hernández 108 (LPAG). Bidens pilosa L., Buenos Aires: Pdo. La Plata, La Plata, 20XI-2011, Hernández 87 (LPAG); 24-IV-2012, Arambarri 379 (LPAG). Conyza bonariensis (L.) Cronquist, Buenos Aires: Pdo. La Plata, La Plata, 5-I-2012, Hernández 96 (LPAG). Galinsoga parviflora Cav., Buenos Aires: Pdo. La Plata, JBA “C. Spegazzini”, FCAyF, UNLP, 3-IX-2012, Arambarri 501 (LPAG). Gamochaeta coarctata (Willd.) Kerguélen, Buenos Aires: Pdo. La Plata, JBA “C. Spegazzini”, FCAyF, UNLP, 4-VI2012, Arambarri 381 (LPAG), 16-VII-2012, Arambarri 382 (LPAG). Mikania micrantha Kunth, Buenos Aires: Pdo. Ensenada, Punta Lara, 10-XI-2008, Colares y Ramos Corrales 50 (LPAG); Pdo. La Plata, Isla Martín 
García, 12-XII-2009, Colares y Martínez 54 (LPAG). Pluchea sagittalis (Lam.) Cabrera, Buenos Aires: Pdo. Ensenada, Isla Santiago, 14-III-2012, Hernández 116 (LPAG). Xanthium spinosum L. Buenos Aires: Pdo. La Plata, La Plata, 29-XII-1972, Dimitri s.n. (LPAG 3678). BORAGINACEAE: Borago officinalis L., Buenos Aires: Pdo. La Plata, Isla Martín García, 22-X-1992, Hurrell \& al. 1255 (LP); Gonnet, 4-X-1998, Delucchi 1846 (LP); Facultad Agronomía, 5-XI-1922, sin colector (LPAG). Echium plantagineum L., Buenos Aires: Pdo. La Plata, Isla Martín García, 22-X-1992, Hurrell \& al. 1257 (LP); La Plata, 14-X-2011, Arambarri 360 (LPAG); La Plata, 4-XI-1998, sin colector (LPAG); Pdo. Ensenada, Punta Lara, 16-X-1979, Volkart s.n. (LPAG). BRASSICACEAE: Lepidium bonariense L., Buenos Aires: Pdo. La Plata, La Plata, 11-X-2011, Arambarri 366 (LPAG); La Plata, Arambarri 368 (LPAG). Lepidium didymum L., Buenos Aires: Pdo. La Plata, La Plata, 14-X-2011, Arambarri 364 (LPAG). Raphanus sativus L., Buenos Aires: Pdo. Mar Chiquita, Santa Clara del Mar, 23-I-1973, Dimitri s.n. (LAPG); Pdo. La Plata, La Plata, 5-X-2011, Arambarri 359 (LPAG). CACTACEAE: Opuntia aurantiaca Lindl., Buenos Aires: Pdo. Escobar, sin loc., IV-1986, Erb (SI 12242). Opuntia ficus-indica (L.) Mill., Buenos Aires: Pdo. Zárate, Lima, 13-XI-1965, Cabrera 17241 (LP). Pdo. Baradero, Baradero, 19-XI1937, Burkart 8500 (SI). Entre Ríos: Dep. Gualeguaychú, Gualeyán, 18-IV-1965, Burkart, Troncoso, Guaglianone 25761 (SI). CAPPARACEAE: Tarenaya hassleriana (Chodat) H.H. Iltis, Entre Ríos: Dep. Paraná, Paraná, 18-V-2012, Albornoz s.n. (LPAG). CHENOPODIACEAE: Dysphania ambrosioides (L.) Mosyakin \& Clemants, Buenos Aires: Pdo. La Plata, Isla Martín García, 20-II-1998, Hurrell \& al. 3891 (LP). Dysphania retusa (Juss. ex Moq.) Mosyakin \& Clemants, Buenos Aires: Pdo. La Plata, Isla Martín García, 13-III-1995, Hurrell \& al. 2401 (LP). EUPHORBIACEAE: Euphorbia serpens Kunth, Buenos Aires: Ciudad Autónoma, 10-II-1966, Amorin s.n. (LPAG); Pdo. La Plata, La Plata, 28-XII2011, Arambarri 375 (LPAG). FABACEAE:
Medicago polymorpha L., Buenos Aires: Pdo. La Plata, JBA “C. Spegazzini”, FCAyF, UNLP, 27-IX-2011, Arambarri 352 (LPAG).

Trifolium repens L., Buenos Aires: Pdo. La Plata, JBA "C. Spegazzini", FCAyF, UNLP, 27-IX-2011, Arambarri 351 (LPAG). FUMARIACEAE: Fumaria capreolata L., Buenos Aires: Pdo. La Plata, JBA "C. Spegazzini”, FCAyF, UNLP, 27-IX-2011, Arambarri 355 (LPAG). GERANIACEAE: Geranium molle L., Buenos Aires: Pdo. La Plata, JBA "C. Spegazzini", FCAyF, UNLP, 27-IX-2011, Arambarri 354 (LPAG). Geranium robertianum L., Buenos Aires: Pdo. La Plata, Isla Martín García, 24-X-1992, Hurrell \& al. 1295 (LP). LAMIACEAE: Marrubium vulgare L., Buenos Aires: Pdo. La Plata, Etcheverry, 7-VII-2002, Martínez 2 (LPAG); Pdo. Punta Indio, Punta Indio, 13-VII-2006, Martínez 106 (LPAG); Pdo. Magdalena, "El Santuario", 28-II-2000, Torres Robles 271 (LP). ONAGRACEAE: Oenothera affinis Cambess., Buenos Aires: Pdo. Campana, Campana, 26-III-2003, Delucchi 2694 (LP); Pdo. Magdalena, Paraje El Pino, 13-IV-1995, Bayón 255 (LPAG). PHYLLANTHACEAE: Phyllanthus niruri L., Entre Ríos: Dep. Paraná, Paraná, 10-XII-2011, Albornoz s.n. (LPAG). PORTULACACEAE: Portulaca oleracea L., Buenos Aires: Pdo. La Plata, JBA "C. Spegazzini”, FCAyF, UNLP, 28-XII-2011, Arambarri 374 (LPAG); Pdo. Ensenada, Isla Santiago, 18-IV-2012, Hernández 122 (LPAG). RANUNCULACEAE: Ranunculus muricatus L., Buenos Aires: Pdo. Lanús, Valentín Alsina, 22-X-1969, Sztaba s.n. (LPAG 1313). Pdo. Ensenada, Isla Santiago, s.f., Cabrera 2263 (LP). URTICACEAE: Parietaria debilis G. Forst., Buenos Aires: Pdo. La Plata, La Plata, 11-XI-2011, Arambarri 365 (LPAG). Urtica urens L., Buenos Aires: Pdo. La Plata, La Plata, 11-XI2011, Arambarri 362, Arambarri 363 (LPAG). SOLANACEAE: Salpichroa origanifolia (Lam.) Baill., Buenos Aires: Pdo. La Plata, Gorina, 18-II-1995, Bayón 103 (LPAG); La Plata, JBA "C. Spegazzini", FCAyF, UNLP, 27-IX-2011, Arambarri 353 (LPAG). VERBENACEAE: Verbena litoralis Kunth, Buenos Aires: Pdo. Magdalena, Reserva 
"E1 Destino", 30-X-2010, Torres Robles \& García 983 bis (LP); Pdo. Ensenada, Isla Santiago, 14-II-2012, Hernández 105 (LPAG). Verbena montevidensis Spreng., Buenos Aires: Pdo. Tigre, Don Torcuato, 1-III- 1984, Orfila s.n. (LPAG); Pdo. La Plata, La Plata, Bayón 190 (LPAG); Pdo. San Pedro, Rincón de San Pedro Dávila de los Arrecifes, XI- 2004, Torres Robles \& Voglino 2402 (LP); Pdo. Berisso, Palo Blanco, 14-IV-1929, Cabrera 861 (LP).

\section{Anatomía, análisis químico y microscopía óptica}

Porciones de la parte media de los tallos se fijaron en solución de formalina-acetoalcohólica (FAA 70\%) (Johansen, 1940). Las muestras de ejemplares de herbario, previamente fueron reconstituidas en agua con una gota de detergente y colocadas en estufa a $30^{\circ} \mathrm{C}$ por $48-72 \mathrm{~h}$, luego fijados en FAA. Se realizaron cortes transversales y longitudinales de los tallos. Las secciones decoloradas fueron teñidas con safranina alcohólica $80 \%$ y violeta de cresilo $1 \%$ y se montaron en gelatina-glicerina (D'Ambrogio de Argüeso, 1986). Se realizaron técnicas histoquímicas para identificar almidón con solución acuosa de Lugol (iodo e ioduro de Potasio, IKI) (Ruzin, 1999); para sustancias lipofílicas se empleó una solución alcohólica saturada de Sudan IV (Johansen, 1940); para sustancias fenólicas (taninos), cloruro férrico al $10 \%$ y carbonato de sodio al $2 \%$ como mordiente (D’Ambrogio de Argüeso, 1986). Para mucílagos se realizó el ensayo fitoquímico (test de precipitado en alcohol) usando alcohol absoluto (Korwar \& al., 2010). Para examinar las estructuras se empleó un microscopio óptico Leitz SM Lux. Las imágenes fueron obtenidas con un microscopio óptico (MO) Gemalux equipado con una cámara PAL CCD y digitalizadas con el software Hyper Media Center y con cámara digital, software y MO Ceti. Para la nomenclatura botánica se sigue a Zuloaga \& al. (2008), URL: www.darwin. edu.ar [Julio de 2012]. La terminología utilizada está de acuerdo con Metcalfe \&
Chalk (1950, 1979). En la Tabla 1, se indican para cada especie (ordenada por familias) los caracteres estructurales del tallo. En el Apéndice 1 se indican para cada especie los usos en medicina popular de los tallos solos, tallos con hojas o cuando se menciona planta entera o parte aérea.

\section{Resultados y Discusión}

Los caracteres estructurales del tallo a nivel familia y en muchos casos a nivel especie han sido tratados por diferentes autores, por lo que se discuten las coincidencias o diferencias halladas con respecto a la bibliografía e incorporan los resultados obtenidos del análisis histoquímico. AMARANTHACEAE (Fig. 2F): se estudiaron los tallos rastreros, cundidores de Alternanthera pungens. Los caracteres estructurales hallados son coincidentes con los descriptos por Barboza \& al. (2001) y el crecimiento anómalo observado fue analizado para el género Alternanthera por Duarte \& Debur (2004). Se encontró una vaina amilífera y escasos amiloplastos en la médula. ASTERACEAE (Figs. 1E; 4A-F; 5A-B): las especies estudiadas de Acmella, Ambrosia, Bidens, Conyza, Galinsoga, Mikania, Pluchea, y Xanthium presentan tallos aéreos erguidos, decumbentes o volubles, de contorno variado en sección transversal (Tabla 1). Todos ellos con estructuras secretoras esquizógenas con epitelio secretor unistrato. Recientemente, estas estructuras fueron estudiadas en profundidad en diversas especies de Asteraceae (Lersten \& Curtis 1987, 1988, 1989; Simon \& al., 2002; Plos \& al., 2011). Con respecto al contenido, Esau (1982) menciona la presencia de resinas; Barboza \& al. (2001) las describen como cavidades resiníferas esquizógenas y Cabrera \& Burkart (1974) indican que contienen aceites esenciales. Cuando realizamos la reacción con Sudan IV se evidenció en las células epiteliales la presencia de gotas oleosas que tomaron color rojo brillante (aceites esenciales). Se encontró aerénquima en la corteza de Acmella decumbens, Mikania 


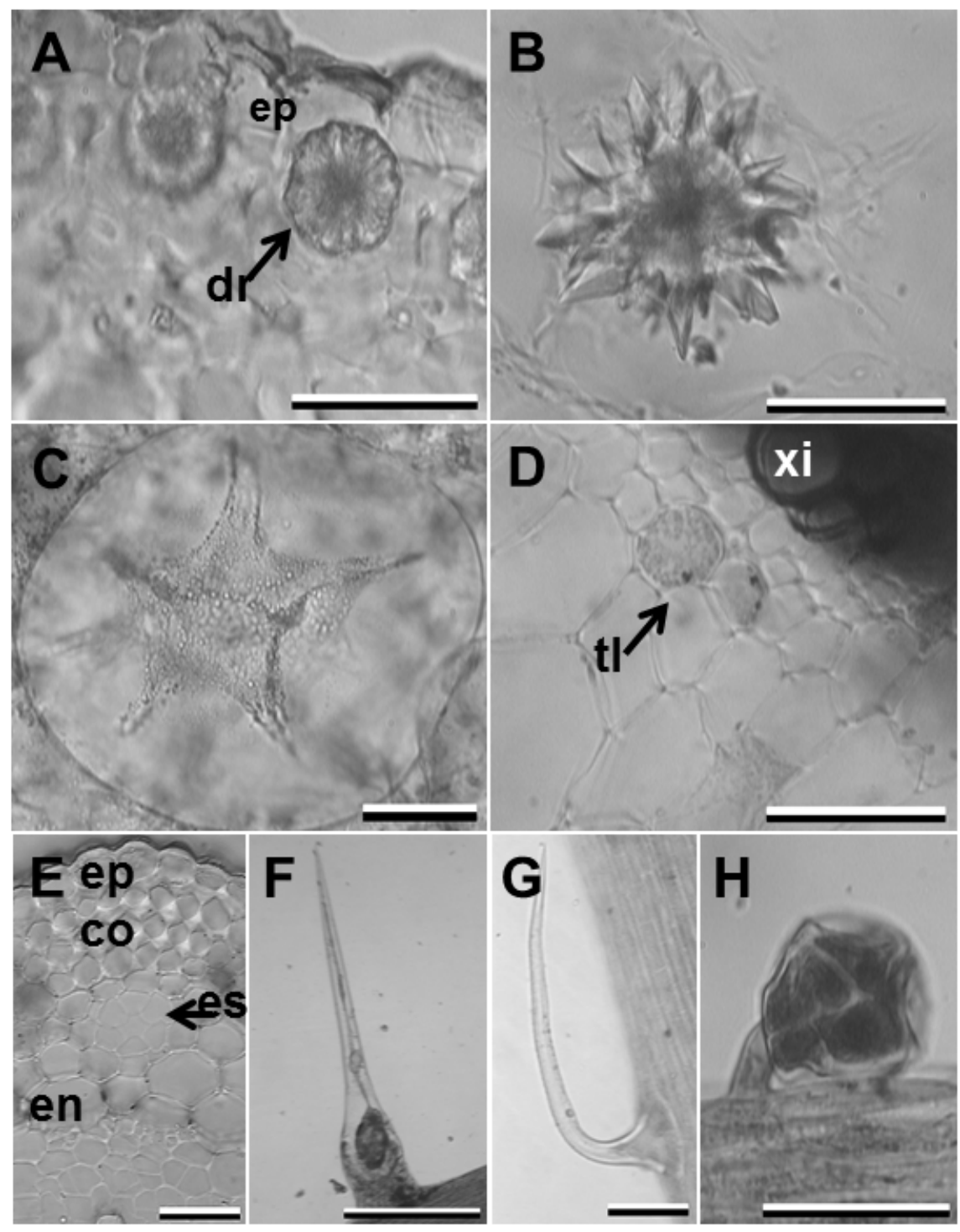

Fig. 1. A-C: Opuntia spp. A: ep, epidermis; dr, drusa de puntas romas del estrato subepidérmico. B: Drusa de puntas agudas en el parénquima interno. C: Estructura secretora mucilaginífera. D: Fumaria capreolata: tl, tubos laticíferos próximos al xilema (xi) de los haces vasculares. E: Bidens pilosa: corte transversal de una costilla secundaria, ep, epidermis; co, colénquima; es, estructura secretora esquizógena; en, endodermis. F-H: Urtica urens. F: Tricoma urticante. G: Tricoma con cistolito en la base. H: Tricoma glandular con pie bicelular y cabeza pluricelular. Escalas: A, B, C, D, E, G, H, $50 \mu \mathrm{m}$. F, $500 \mu \mathrm{m}$.

micrantha y Pluchea sagittalis. La presencia de aerénquima en los tallos es una adaptación a suelos con deficiente aireación (Ancibor, 1980; Apóstolo, 2005). En Acmella también se encontraron células pétreas en la corteza. Los caracteres hallados en Pluchea sagittalis fueron descriptos por Cambi \& al. (2006) y la anatomía de Bidens pilosa fue descripta por Santos \& Cury (2011), con cuya descripción coincidimos incluso en la presencia de almidón en la endodermis. Ambrosia tenuifolia y Xanthium spinosum poseen estructura de los tallos similares entre sí. En $A$. tenuifolia no se observaron las 


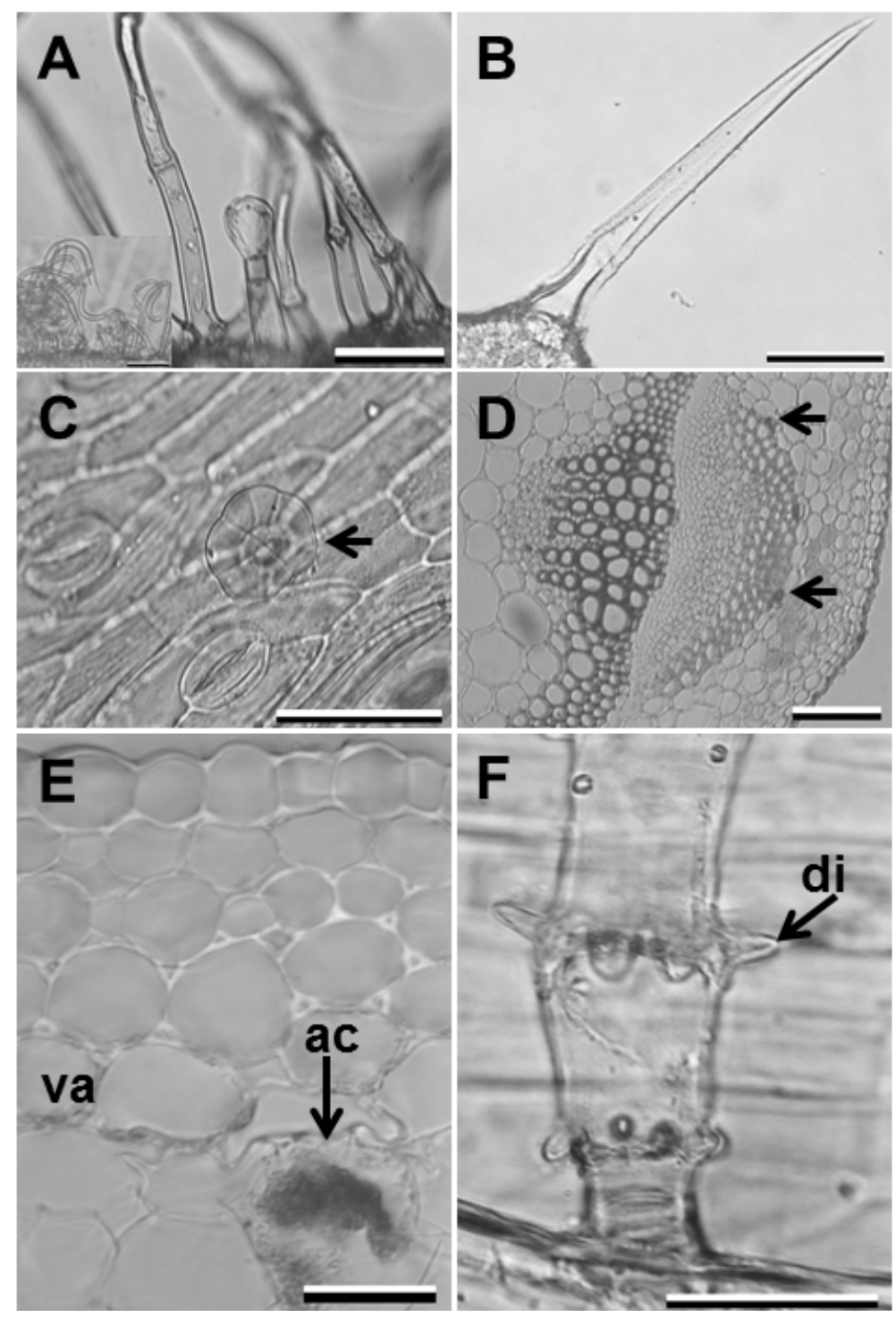

Fig. 2. A: Marrubium vulgare: detalle de la pubescencia glandular y eglandular; en el margen inferior izquierdo una vista general de la pubescencia lanosa. B: Verbena litoralis: tricoma cónico, simple, unicelular. C: Verbena montevidensis: tricoma glandular mostrando la cabeza pluricelular. D: Medicago polymorpha: vista de un haz vascular, las flechas señalan cristales en la vaina. E: Salpichroa origanifolia: ac, arena cristalina; va, vaina amilífera. F: Alternathera pungens: di, diente de la unión dentada entre células del tricoma pluricelular. Escalas: A, vista general $100 \mu \mathrm{m}$, detalle: $50 \mu \mathrm{m}$. B, $100 \mu \mathrm{m}$. C-F, $50 \mu \mathrm{m}$.

drusas mencionadas por Lovisolo \& al. (2003), lo cual podría deberse a las condiciones del suelo donde la especie estuvo creciendo ya que la acumulación de cristales está influenciada por el contenido de iones y pH del suelo (Apóstolo, 2005). Los caracteres encontrados en Xanthium spinosum fueron previamente descriptos por
Barboza \& al. (2001). El estudio histoquímico permitió detectar almidón en las células oclusivas de los estomas y en la endodermis de los tallos de Bidens pilosa, Galinsoga parviflora y Pluchea sagittalis. En Achirochline satureoides los caracteres estructurales observados fueron coincidentes con lo referido por Gattuso \& Gattuso 

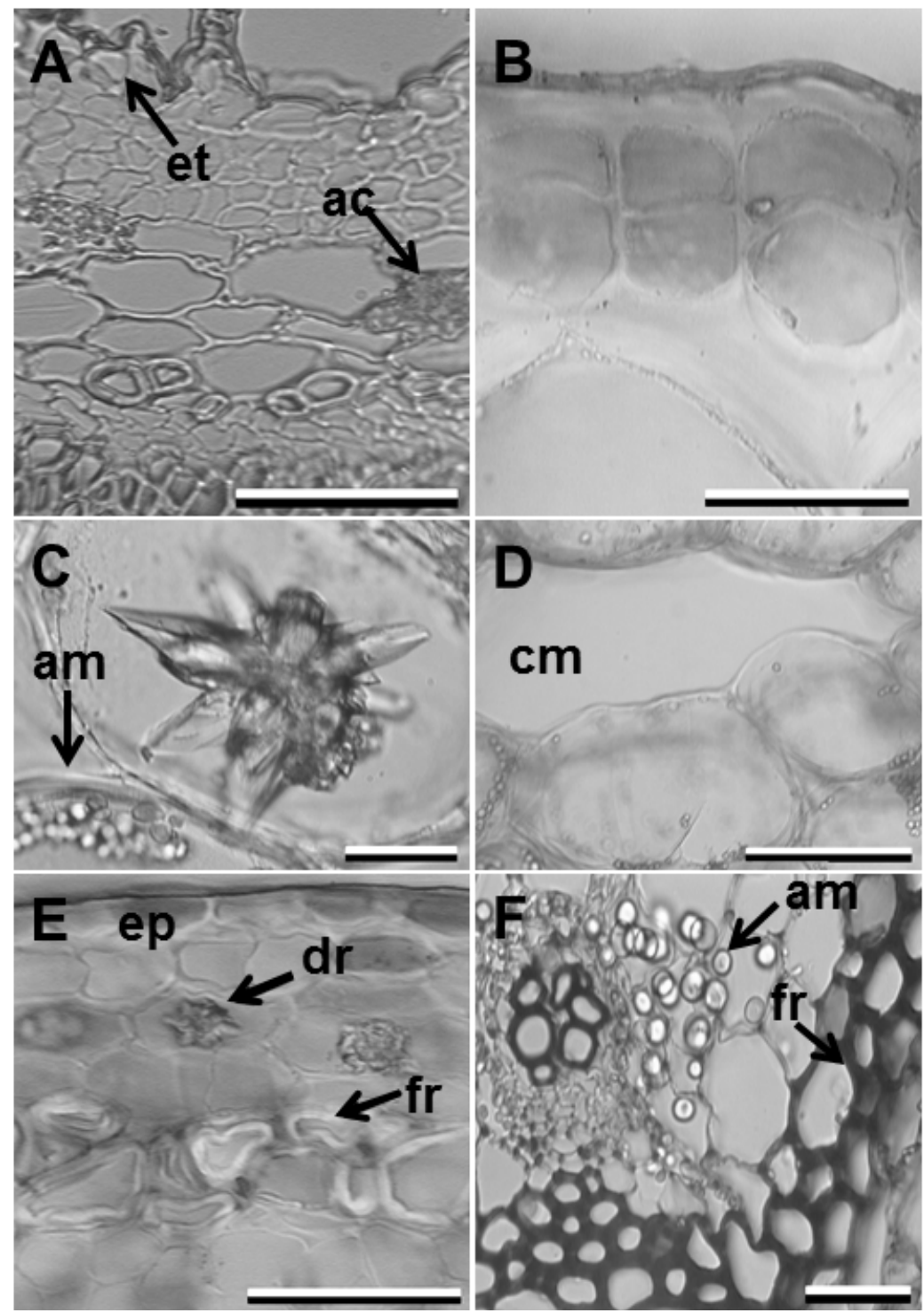

Fig. 3. A: Dysphania retusa: ac, arena cristalina en el parénquima; et, estoma ubicado a nivel con respecto a las restantes células epidérmicas. B-D: Portulaca oleracea. B: Epidermis bistrata. C: Drusa con puntas agudas, am, amiloplastos en el parénquima. D: cm, cavidad mucilaginífera. E: Phyllanthus niruri: ep, epidermis glabra; dr, drusas en el parénquima cortical; fr, fibras. F: Geranium robertianum: am, amiloplastos conspicuos; fr, anillo de fibras. Escalas: A- F, $50 \mu \mathrm{m}$.

(1998). No hallamos estructuras secretoras en los tallos de esta especie ni en los de Gamochaeta coarctata. BORAGINACEAE (Fig. 6D): se analizaron los tallos erguidos de Borago oficinalis y Echium plantagineum, los que presentaron caracteres similares (Tabla 1). Su anatomía se corresponde con los rasgos señalados para la familia (Metcalfe \& Chalk, 1950; Selvi \& Bigazzi, 2001;
Monti \& al., 2003). Al realizar la determinación de almidón se detectó una vaina amilífera. BRASSICACEAE (Figs. 5C, D; 6C): Las especies estudiadas presentan tallos ascendentes a erguidos con caracteres similares. En Lepidium didymum la corteza presenta colénquima continuo como fuera referido por Barboza \& al. (2001); en $L$. bonariense se halló una corteza 

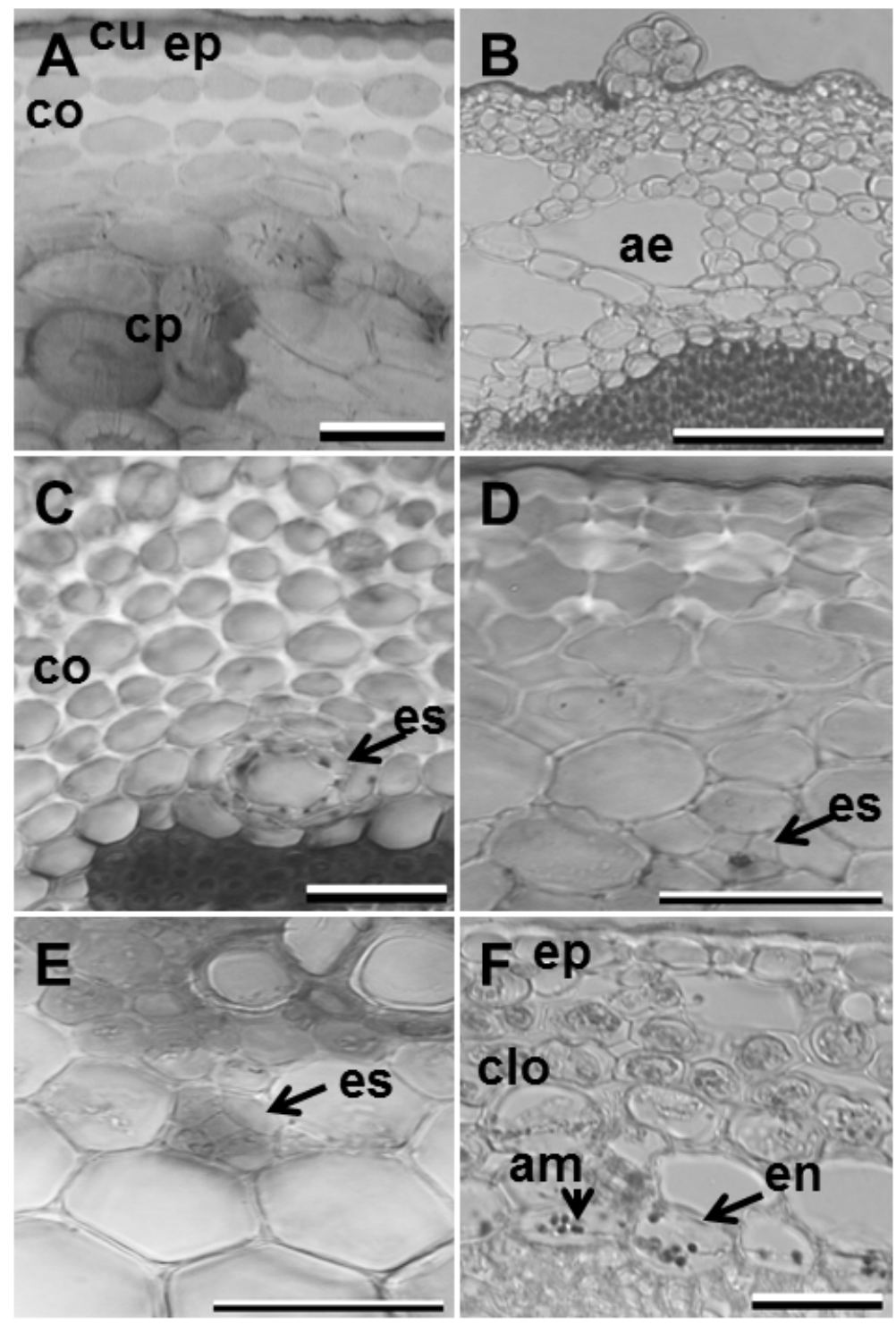

Fig. 4. A: Acmella decumbens: cu, cutícula; ep, epidermis; co, colénquima laminar; cp, células pétreas en el parénquima cortical. B: Pluchea sagittalis: ae, aerénquima; tr, tricoma. C: Conyza bonariensis: co, colénquima angular; es, estructura secretora esquizógena. D-F: Galinsoga parviflora. D: ep, epidermis colenquimatosa; co, colénquima angular; es, estructura secretora cortical. E: es, estructura secretora medular junto al xilema (xi). F: ep, epidermis; clo, clorénquima; en, endodermis con banda de Caspary; am, amiloplastos. Escalas: A, C-F, $50 \mu \mathrm{m}$. B, $200 \mu \mathrm{m}$.

parenquimática y en Raphanus sativus colénquima discontinuo. Las tres especies presentan epidermis notablemente colenquimatosa. Se encontró almidón en las células oclusivas de los estomas y se evidenció una vaina amilífera. CACTACEAE (Fig. 1A-C): se estudió la estructura de los cladodios de Opuntia aurantiaca y O. ficus- indica, cuya anatomía muestra gran uniformidad de caracteres y resultó coincidente con datos reportados por Metcalfe \& Chalk (1950) y Fahn \& Cuttler (1992). CAPPARACEAE (Fig. 6B): se estudiaron los tallos erguidos de Tarenaya hassleriana. La epidermis es unistrata con estomas a nivel e indumento denso formado 



Fig. 5. A: Ambrosia tenuifolia: un haz vasccular: fl, floema, xi, xilema; cv, cambium vascular; mp, médula parenquimática maciza. B: Gamochaeta coarctata: ep, epidermis; cp, corteza parenquimática; en, endodermis conspicua rodeando el cilindro vascular. C-D: Rapahus sativus. C: av, anillo vascular sinuoso. D: et, estoma; va, vaina amilífera. E: Euphorbia serpens: tl, tubo laticífero a nivel de las fibras que rodean el cilindro vascular. F: Parietaria debilis: estoma sobre el nivel (elevado) de las restantes células epidérmicas. Escalas: A, $100 \mu \mathrm{m} \mathrm{B}, \mathrm{D}-\mathrm{F}, 50 \mu \mathrm{m}$. C, $1 \mathrm{~mm}$.

por tricomas glandulares. La corteza está formada por colénquima seguido de parénquima hasta el cilindro vascular secundario que rodea la médula parenquimática. CHENOPODIACEAE (Fig. 3A): se estudiaron los tallos erguidos de Dysphania ambrosioides y D. retusa. Los caracteres generales de la familia son coincidentes con los señalados en trabajos previos (Ancibor, 1980; Simon, 1987; D’Ambrogio \& al., 2000; Barboza \& al., 2001; Apóstolo, 2005). La descripción de la estructura anómala fue realizada por Metcalfe \& Chalk $(1950,1989)$. La presencia de vaina amilífera fue mencionada por D'Ambrogio $\&$ al. (2000) y Barboza \& al. (2001). En el 


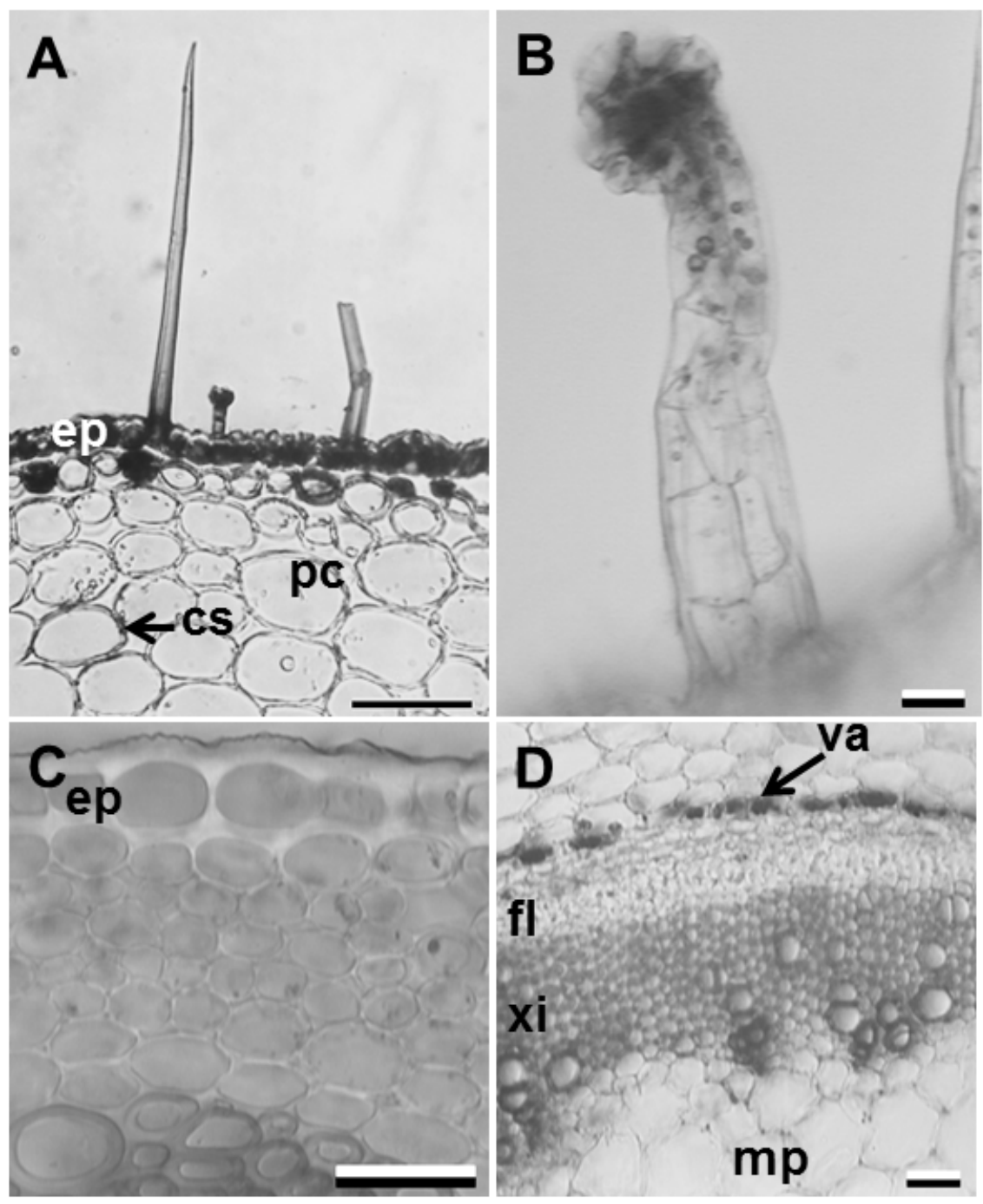

Fig. 6. A: Geranium molle: ep, epidermis con tricomas eglandular cónico y glandular; cs, célula secretora; pc, parénquima cortical. B: Tarenaya hassleriana: tricoma glandular, pluricelular, pluriseriado, capitado. C: Lepidium bonariense: ep, epidermis colenquimatosa. D: Echium plantagineum: va, vaina amilífera limitando el cilindro vascular; fl, floema secundario; xi, xilema secundario; mp, amplia médula parenquimática. Escalas: A, $100 \mu \mathrm{m}$. B-D, $50 \mu \mathrm{m}$.

material estudiado se observó almidón en las células oclusivas de los estomas además de una vaina amilífera. EUPHORBIACEAE (Fig. 5E): se estudiaron los tallos ramificados, radicantes y glabros de Euphorbia serpens. Los caracteres estructurales fueron referidos por Barboza \& al. (2001). Se obtuvo reacción positiva para almidón en los parénquimas cortical y medular. FABACEAE (Fig. 2D): se estudiaron los tallos endebles y angulosos de Medicago polymorpha y los cilíndricos, rastreros y radicantes de Trifolium repens. Las dos especies presentan tricomas glandulares y eglandulares. Los tricomas de T. repens, fueron tratados por Freire \& al. (2005) y Yagueddú \& al. (2009). En $M$. polymorpha hay colénquima angular en las costillas del tallo, mientras que la corteza es totalmente parenquimática en el tallo de $T$. repens. En ambas especies la reacción para almidón fue positiva en la vaina parenquimática cristalífera del cilindro 
vascular. FUMARIACEAE (Fig. 1D): se estudiaron los tallos erguidos hasta decumbentes y volubles, difusamente ramificados y glabros de Fumaria capreolata. $\mathrm{Si}$ bien, la estructura hallada coincide con la descripta por Lujan \& al. (2004), se hallaron algunos tallos con cinco costillas, dos de ellas muy próximas, de manera que a veces, se fusionan y forman tan sólo cuatro y no observamos cristales lo cual se puede atribuir a las características del suelo donde la planta creció (Apóstolo, 2005). Se obtuvo reacción positiva para almidón en las células oclusivas de los estomas, en dos estratos celulares subepidérmicos y en la vaina parenquimática de los haces vasculares. GERANIACEAE (Figs. 3F; 6A): se estudiaron los tallos ascendentes de Geranium molle y $G$. robertianum. El indumento de la epidermis es coincidente con Freire \& al. (2005). En ambas especies se observa un anillo fibroso en cuya adyacencia se ubican los haces vasculares colaterales formando la eustela. Como lo describe Metcalfe \& Chalk (1950), en $G$. robertianum la eustela presenta dos ciclos de haces vasculares; se observó que el ciclo externo, adyacente al anillo de fibras tiene mayor número de haces colaterales y de menor tamaño que el ciclo interno. En ambas especies se obtuvo reacción positiva para almidón por la presencia de abundantes amiloplastos en todos los parénquimas. LAMIACEAE (Fig. 2A): se estudió el tallo erguido y robusto de Marrubium vulgare cuyas características fueron previamente descriptas por Barboza \& al. (2001). La reacción fue negativa para almidón. ONAGRACEAE: se analizó el tallo erguido de Oenothera affinis. El indumento epidérmico es denso. La corteza presenta anillo fibroso y endodermis y el cilindro vascular crecimiento secundario. La médula es fistulosa. La presencia de rafidios es un carácter diagnóstico de la familia (Metcalfe \& Chalk, 1950). Se detectó almidón en la corteza. PHYLLANTHACEAE (Fig. 3E): se estudió el tallo erguido y delgado de Phyllanthus niruri. En todos los parénquimas se obtuvo reacción positiva para almidón. PORTULACACEAE (Fig. 3B-D): se estudió el tallo postrado, muy ramificado de
Portulaca oleracea. Las células epidérmicas presentan paredes periclinales engrosadas, la eustela está formada por pequeños haces vasculares que rodean una amplia médula parenquimática. En el parénquima hay numerosos amiloplastos. Las drusas son uno de los caracteres diagnóstico de acuerdo con Figueroa \& al. (2011). RANUNCULACEAE: se estudiaron los tallos ascendentes, de Ranunculus muricatus. En la epidermis son característicos los tricomas unicelulares agudos y en la corteza la ausencia de colénquima. La reacción para almidón resultó positiva en la vaina de los haces vasculares y en el parénquima medular. SOLANACEAE (Fig. 2E): Se estudiaron los tallos erguidos o ascendentes muy ramificados de Salpichroa origanifolia. La presencia de haces bicolaterales y arena cristalina son propios de la familia Solanaceae y lo mismo ocurre con la vaina amilífera que es un carácter frecuente en especies o tribus de la familia (Cosa, 1991a; 1991b). La estructura del tallo fue estudiada por Colares \& al. (1999) y más recientemente por Stiefkens \& al. (2010), quienes destacan los rasgos anatómicos como elementos de valor diagnóstico útiles en la identificación de las especies. URTICACEAE (Figs. 1F-H; 5F): se estudiaron los tallos ascendentes débiles, muy ramificados de Parietaria debilis y los tallos erguidos robustos y poco ramificados de Urtica urens. Se coincide con las descripciones realizadas por Barboza \& al. (2001) para ambas especies, tales como la presencia y tipos de tricomas eglandulares y glandulares. Se agrega la presencia de almidón formando una vaina amilífera y amiloplastos en los parénquimas cortical, medular y del floema de U. urens. En $P$. debilis se menciona por primera vez la posición de los estomas respecto al nivel de las restantes células epidérmicas. VERBENACEAE (Fig. 2B-C): se estudiaron los tallos erguidos de Verbena litoralis y $V$. montevidensis. Las características generales se corresponden con las del género y la familia (Metcalfe \& Chalk, 1950; Bonzani \& al., 2003). Se detectó almidón en las células oclusivas de los estomas, en el parénquima cortical y en la endodermis. 







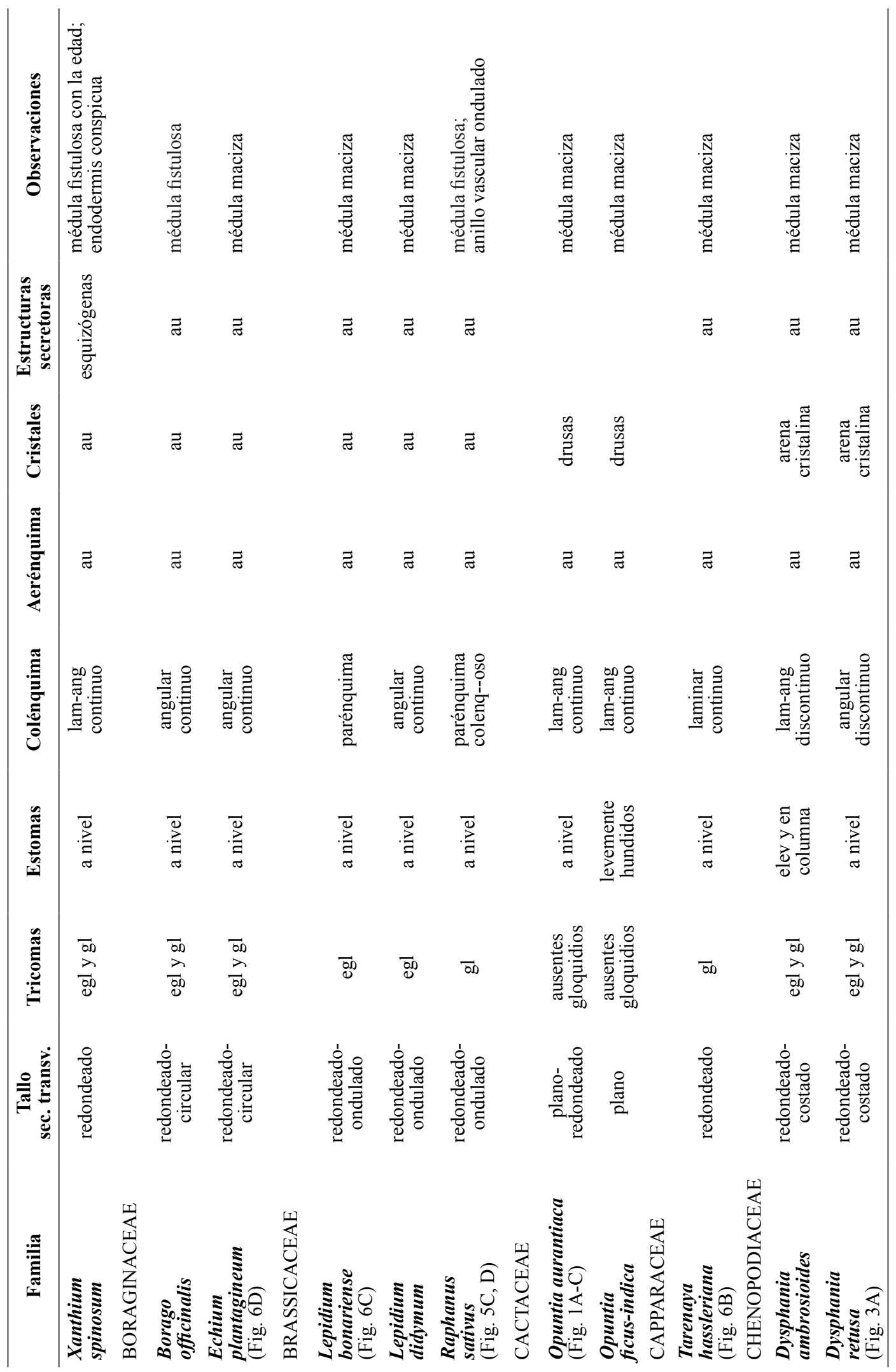









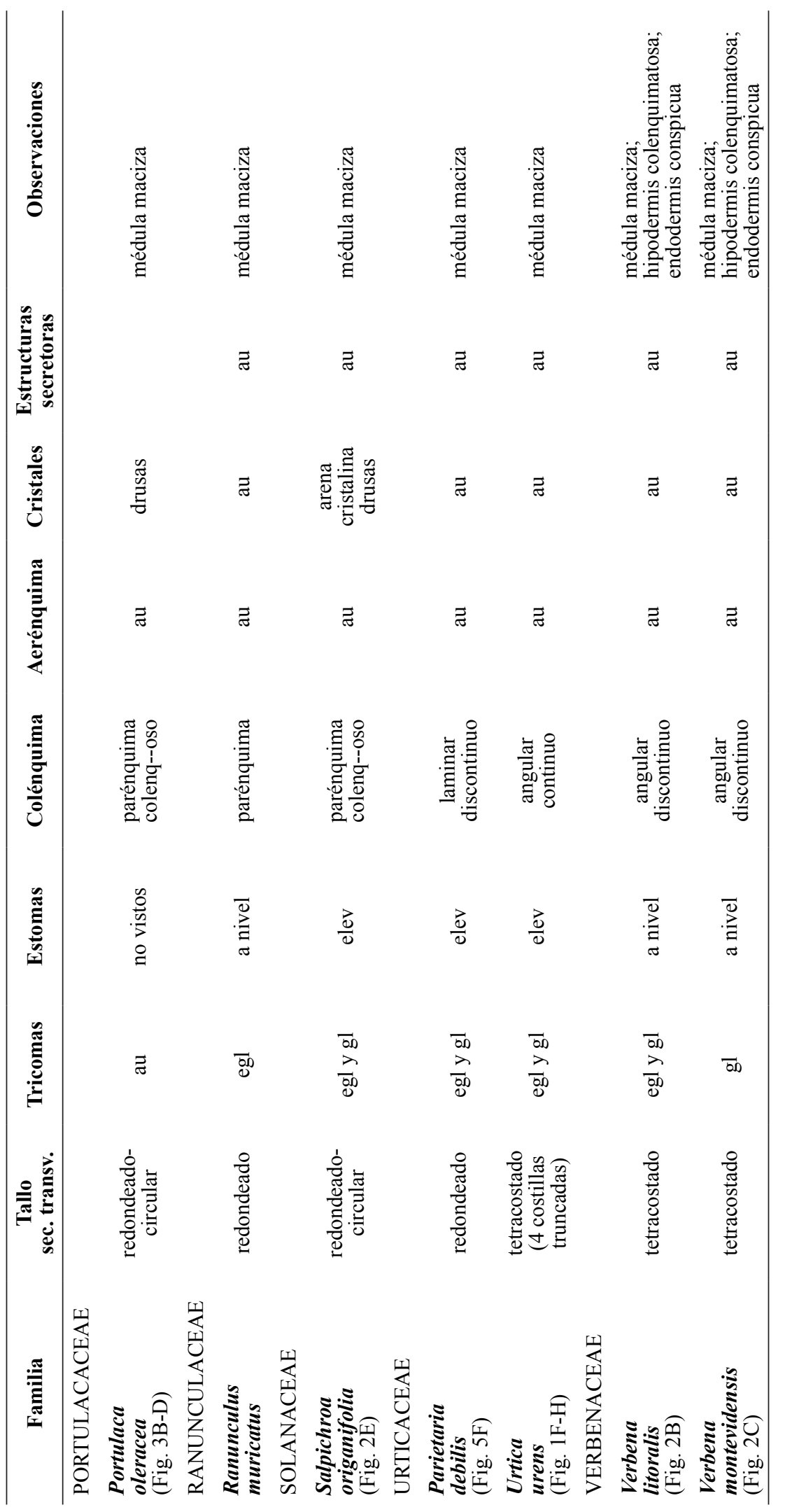




\section{Conclusiones}

Los caracteres diagnóstico hallados en la morfo-histología de los tallos de las 37 especies medicinales estudiadas permiten concluir con la siguiente clave dicotómica para su identificación:

1.Cladodios. Presencia en el mismo tallo de dos formas de drusas: drusas con puntas romas en un estrato subepidérmico y drusas con puntas agudas en el parénquima interno.

2. Cladodios plano-redondeados. Estomas a nivel.

1. Opuntia aurantiaca

2'. Cladodios planos. Estomas levemente hundidos.

2. Opuntia ficus-indica

1'. Tallos aéreos normales, nunca cladodios. Ausencia en el mismo tallo de dos formas de drusas (cuando están presentes).

3. Contorno de la sección transversal del tallo: tetragonal (tetracostado), por excepción, 5-costado (Fumaria).

4. Tallos glabros. Presencia de tubos laticíferos en la proximidad del xilema.

3. Fumaria capreolata

4'. Tallos pubescentes. Ausencia de tubos laticíferos en la proximidad del xilema.

5. Tallos con un conducto esquizógeno en el colénquima de cada una de las costillas principales. Costillas secundarias poco prominentes con un conducto en el parénquima.

4. Bidens pilosa

5'. Tallos nunca con conductos esquizógenos en el colénquima de las costillas principales. Costillas secundarias ausentes.

6. Presencia de pelos urticantes. Haces vasculares agrupados en las costillas.

5. Urtica urens

6'. Ausencia de pelos urticantes. Haces vasculares nunca agrupados en las costillas.

7. Tallos con indumento denso. Tricomas eglandulares uni-pluricelulares, algunos estrellados y glandulares con pie corto y largo y cabeza uni-pluricelular. Estomas elevados sobre el nivel de las restantes células epidérmicas, incluso en columna.

6. Marrubium vulgare

7'. Tallos con indumento escaso. Tricomas eglandulares, uni-bicelulares, nunca estrellados y glandulares con pie corto y cabeza pluricelular. Estomas a nivel o sólo levemente elevados con respecto a las restantes células epidérmicas.

8. Espacios intercostales con hipodermis colenquimatosa. Endodermis conspicua. Vaina cristalífera ausente.

9. Presencia de tricomas eglandulares cónicos, simples, unicelulares.

8. Verbena litoralis

9'. Ausencia de tricomas eglandulares cónicos, simples, unicelulares.

7. Verbena montevidensis

8'. Espacios intercostales sin hipodermis. Endodermis inconspicua. Vaina cristalífera presente.

9. Medicago polymorpha

3'. Contorno de la sección transversal del tallo redondeado (redondeado-circular; redondeado-ondulado o redondeado-multicostado).

10. Presencia de rafidios.

10. Oenothera affinis 
$10^{\prime}$. Ausencia de rafidios.

11. Presencia de arena cristalina.

12. Eustela con haces bicolaterales.

20. Salpichroa origanifolia

$12^{\prime}$. Eustela con haces colaterales.

13. Presencia de drusas. Tricomas eglandulares, pluricelulares con unión dentada entre células.

21. Alternanthera pungens

$13^{\prime}$. Ausencia de drusas. Tricomas eglandulares sin esas características.

14. Epidermis con estomas a nivel con respecto a las restantes células epidérmicas.

22. Dysphania retusa

14'. Epidermis con estomas sobre el nivel (elevados) con respecto a las restantes células epidérmicas.

23. Dysphania ambrosioides

11 '. Ausencia de arena cristalina.

15. Presencia de drusas.

16. Tallo de consistencia crasa. Epidermis bistrata, parénquima con drusas proporcionalmente grandes. Presencia de estructuras mucilaginíferas. Ausencia de fibras.

24. Portulaca oleracea

16'. Tallo nunca de consistencia crasa. Epidermis unistrata, parénquima con drusas proporcionalmente pequeñas. Ausencia de estructuras mucilaginíferas. Presencia de fibras.

17. Tallo glabro. Anillo discontinuo de fibras corticales (1-2 estratos).

25. Phyllanthus niruri

17'. Tallo pubescente. Anillo continuo de fibras corticales (2-4 estratos).

26. Geranium robertianum

$15^{\prime}$. Ausencia de drusas.

18. Estructuras secretoras esquizógenas en la corteza o en la corteza y en la médula.

19. Tallos con aerénquima cortical.

20. Tallos decumbentes. Corteza con células pétreas.

11. Acmella decumbens

20'. Tallos erguidos o volubles. Corteza sin células pétreas.

21. Tallos erguidos, en corte transversal con "alas" de origen foliar.

12. Pluchea sagittalis

21 '. Tallos volubles, en corte transversal sin "alas" de origen foliar.

13. Mikania micrantha

19'. Tallos sin aerénquima cortical.

22. Estructuras secretoras enfrentadas a los haces vasculares únicamente.

14. Conyza bonariensis

22 '. Estructuras secretoras enfrentadas a los radios medulares y también en la médula.

23. Contorno de la sección transversal del tallo redondeado-ondulado (costillas numerosas poco prominentes). Endodermis con almidón.

15. Galinsoga parviflora 
23'. Contorno de la sección transversal del tallo redondeado-circular (costillas ausentes). Endodermis sin almidón.

24. Médula fistulosa a la madurez.

16. Xanthium spinosum

24'. Médula maciza.

17. Ambrosia tenuifolia

18'. Estructuras secretoras esquizógenas ausentes.

25. Tallos con endodermis conspicua.

26. Tallos de sección transversal redondeado-ondulado (costillas levemente manifiestas). Corteza con colénquima laminar.

18. Achyrocline satureoides

26'. Tallos de sección transversal redondeado-circular (costillas ausentes). Corteza totalmente parenquimática.

19. Gamochaeta coarctata

25'. Tallos con endodermis inconspicua o ausente.

27. Anillo o grupos de fibras corticales o floemáticas presentes. Vaina amilífera conspicua o inconspicua.

28. Anillo vascular sinuoso. Vaina amilífera conspicua.

27. Raphanus sativus

28'. Anillo vascular no sinuoso. Vaina amilífera inconspicua.

29. Presencia de tubos laticíferos alternando con las fibras.

28. Euphorbia serpens

29'. Ausencia de tubos laticíferos.

30. Estomas sobre el nivel (elevados) con respecto a las restantes células epidérmicas.

31. Tricomas glandulares escasos. Tricomas eglandulares con cistolito en la base, o con el ápice curvado en forma de gancho (uncinulados).

29. Parietaria debilis

31'. Tricomas glandulares numerosos. Tricomas eglandulares cónicos, unibicelulares, sin cistolito en la base, y con el ápice recto, agudo.

30. Geranium molle

$30^{\prime}$. Estomas a nivel o levemente elevados con respecto a las restantes células epidérmicas.

32. Pubescencia densa. Tricomas glandulares, pluriseriados. Tricomas eglandulares ausentes.

31. Tarenaya hassleriana

32'. Pubescencia escasa. Tricomas glandulares uniseriados. Tricomas eglandulares presentes.

33. Epidermis colenquimatosa. Corteza con colénquima o parénquima.

34. Corteza con colénquima angular.

32. Lepidium didymum

34'. Corteza parenquimática.

33. Lepidium bonariense

33'. Epidermis no colenquimatosa. Corteza parenquimática. 
35. Tricomas solamente eglandulares. Cutícula lisa.

34. Ranunculus muricatus

$35^{\prime}$. Tricomas eglandulares y glandulares. Cutícula estriada.

35. Trifolium repens

27'. Anillo o grupos de fibras corticales o floemáticas ausentes. Vaina amilífera conspicua.

36. Médula fistulosa.

36. Borago officinalis

36'. Médula maciza.

37. Echium plantagineum

\section{Agradecimientos}

A los curadores de los herbarios LP, LPAG y SI por facilitar el material vegetal. A los revisores por la lectura crítica del manuscrito y sugerencias brindadas que ayudaron a mejorar el mismo. A la Secretaría de Ciencia y Técnica de la Universidad Nacional de La Plata por el financiamiento económico de los estudios.

\section{Bibliografía}

ALONSO, J. R. 1998. Tratado de fitomedicina. Bases clínicas y farmacológicas. ISIS ediciones SRL, Buenos Aires, pp. 985-987.

\& C. DESMARCHELIER. 2005. Plantas medicinales autóctonas de la Argentina. Bases Científicas para su Aplicación en Atención Primaria de la salud. L.O.L.A. (Literature of Latin America), Buenos Aires. 663 pp.

AMAT, A. G. \& M. E. YAJÍA. 1991. Plantas medicinales y etnofarmacología en la provincia de Misiones (Argentina). Acta Farm. Bonaerense 10(3): 153159.

ANCIBOR, E. 1980. Estudio anatómico de la vegetación de la Puna de Jujuy. II. Anatomía de las plantas en cojín. Bol. Soc. Argent. Bot. 19(1-2): 157-202.

APÓSTOLO, N. M. 2005. Caracteres anatómicos de la vegetación costera del Río Salado (Noroeste de la provincia de Buenos Aires, Argentina). Bol. Soc. Argent. Bot. 40(3-4): 215-227.

BARBOZA, G. E., N. BONZANI, E. M. FILIPPA, M. C. LUJÁN, R. MORERO, M. BUGATTI, N. DECOLATTI \& L. ARIZA ESPINAR. 2001. Atlas histo-morfológico de plantas de interés medicinal de uso corriente en Argentina. Museo Botánico de Córdoba, Ser. Especial 1, 212 pp. , J. J. CANTERO, C. O. NÚÑEZ \& L. ARIZA
ESPINAR. 2006. Flora medicinal de la provincia de Córdoba (Argentina), Museo Botánico de Córdoba, Gráficamente ediciones, Córdoba. 1264 pp.

BOERIS, M. A., R. E. TOSO \& M. I. SKLIAR. 2004. Actividad antiinflamatoria de Salpichroa origanifolia. Acta Farm. Bonaerense 23(2): 138-141.

BONZANI, N. E., E. M. FILIPPA \& G. E. BARBOZA. 2003. Estudio anatómico comparativo de tallo en algunas especies de Verbenaceae. Anales Inst. Biol. Univ. Nac. Mexico 74(1): 31-45.

BURKART, A. 1957. Ojeada sinóptica sobre la vegetación del Delta del río Paraná. Darwiniana 11: 475-563.

CABRERA, A. L. 1949. Las comunidades vegetales de los alrededores de La Plata Provincia de Buenos Aires, República Argentina. Lilloa 20: 269-274.

- 1963. Flora de la provincia de Buenos Aires. Vol. 4, parte 6, Colección Cientif. INTA. 443 pp.

_ \& G. DAWSON. 1944. La selva marginal de Punta Lara en la ribera argentina del Río de La Plata. Revista Museo de La Plata, Secc. Bot. 5: 267-382.

— \& A. BURKART. 1974. Compositae. En A. Burkart, (dir.), Flora ilustrada de Entre Ríos (Argentina), Colecc. Cientif. INTA 6(6): 107-110.

— \& E. M. ZARDINI. 1978. Manual de la flora de los alrededores de Buenos Aires, 2 ed., Ed. Acme, Buenos Aires. 755 pp.

CAMBI, V., A. BUCCIARELLI, A. FLEMMER \& P. HANSEN. 2006. Morfoanatomía de Pluchea sagittalis (Asteraceae), especie nativa de interés medicinal. Acta Farm. Bonaerense 25(1): 43-49.

CARRIZO, E., M. O. PALACIO \& L. D. ROIC $(e x$ aequo). 2002. Plantas de uso medicinal en la flora de los alrededores de la ciudad de Santiago del Estero (Argentina). Dominguezia 18(1): 26-35.

- 2005. Uso medicinal de algunas especies nativas en Santiago del Estero (República Argentina). Dominguezia 21(1): 25-32.

CHIFA, C. \& A. I. A. RICCIARDI. 2001. Plantas de uso en medicina vernácula del centro del Chaco argentino. Fundación Miguel Lillo, Tucumán, 117: 3-33. 
COLARES, M. 2011. Mikania cordifolia y Mikania micrantha (Asteraceae): especies medicinales nativas de las reservas naturales de Punta Lara e Isla Martín García, Buenos Aires, Argentina. Tesis de Magister en Plantas Medicinales, Facultad de Ciencias Exactas, SEDICI, UNLP.

—, N. D. BAYÓN, S. A. STENGLEIN \& A. M. ARAMBARRI. 1999. Anatomía y etnobotánica de las especies medicinales de la provincia pampeana: Solanaceae (excepto Grabowskia y Solanum). Acta Farm. Bonaerense 18(3): 171-182.

COSA, M. T. 1991a. Estudio morfoanatómico de órganos vegetativos en Cestroideae (Solanaceae). I: Tribu Nicotineae. Kurtziana 21: 111-152.

—_ 1991b. Estudio morfoanatómico de órganos vegetativos en Cestroideae (Solanaceae). II: Tribu Salpiglossideae. Kurtziana 22: 47-72.

D’AMBROGIO DE ARGÜESO, A. 1986. Manual de técnicas en histología vegetal. Ed. Hemisferio Sur, Buenos Aires. 86 pp.

— N. FRAYSSINET. 2000. Estudios morfoanatómicos y citológicos en Atriplex sagittifolia (Chenopodiaceae). Bol. Soc. Argent. Bot. 35(3-4): 215-226.

DOMÍNGUEZ, J. A. 1928. Contribuciones a la materia médica argentina. Instituto de Botánica y Farmacología (Facultad de Ciencias Médicas de Buenos Aires), Ed. Peuser, Buenos Aires. 433 pp.

DUARTE, M. R. \& M. C. DEBUR. 2004. Characters of the leaf and stem morpho-anatomy of Alternanthera brasiliana (L.) O. Kuntze, Amaranthaceae. Brazilian J. Pharmacol. Sci. 40(1): 85-92.

ESAU, K. 1982. Anatomía de las plantas con semilla. Ed. Hemisferio Sur, Buenos Aires. 512 pp.

FAHN, A. \& D. F. CUTTLER. 1992. Xerophytes In Encyclop. P1. Anat. Vol. 1, Part 9, pp. 56-57. Gebrüder Borntraeger, Berlín.

FIGUEROA, S. D., N. DOTTORI \& M. T. COSA. 2011. Anatomía vegetativa de Portulaca oleracea (Portulacaceae), especie de interés medicinal. XXXIII Jornadas Argentinas de Botánica, Bol. Soc. Argent. Bot. 46(supl.): 95.

FREIRE, S. E. \& E. URTUBEY. 1999. Compuestas medicinales de la provincia biogeográfica pampeana: Claves para su determinación e iconografías. Parte 1: Compuestas espinosas (grupo 1) y Compuestas con tallos alados (grupo 2). Acta Farm. Bonaerense 18(3): 191-199.

- 2000a. Compuestas medicinales de la provincia biogeográfica pampeana: Claves para su determinación e iconografías. Parte 3. Compuestas con capítulos isomorfos y papus no piloso o ausente (Grupo 4). Acta Farm. Bonaerense 19(1): 13-16. 2000b. Compuestas medicinales de la provincial biogeográfica pampeana: Claves para su determinación e iconografías. Parte 5. Compuestas con capítulos dimorfos o trimorfos y con papus
(Grupos 6 y 7). Acta Farm. Bonaerense 19(3): 165184.

,A. M. ARAMBARRI, N. D. BAYÓN, G. SANCHO, E. URTUBEY, C. MONTI, M. C. NOVOA \& M. N. COLARES. 2005. Epidermal characteristics of toxic plants for cattle from the Salado river basin (Buenos Aires, Argentina). Bol. Soc. Argent. Bot. 40(3-4): 241-281.

GATTUSO, S. J. \& M. A. GATTUSO. 1998. Caracteres anatómicos y exomorfológicos distintivos de Achyrocline satureioides (Lam.) DC. (AsteraceaeInuleae). Acta Farm. Bonaerense 17(4): 255-261.

HAUMAN, L. 1925. La vegetation de l'lle Martin Garcia dans le Rio de La Plata, Publicación del Instituto de Investigación Geográfica, Facultad de Filosofía y Letras, Universidad de Buenos Aires. 39 pp.

HERNÁNDEZ, M. P., S. M. COLARES \& S. M. CIVITELLA. 2009. Plantas utilizadas en medicina popular en un sector del Partido de Berisso, Buenos Aires, Argentina. Bol. Latinoam. Caribe Plant Med. Aromat. 8(5): 435-444.

_ S. M. CIVITELLA \& V. G. ROSATO. 2010. Uso medicinal popular de plantas y líquenes de la Isla Paulino, Provincia de Buenos Aires, Argentina. Bol. Latinoam. Caribe Plant Med. Aromat. 9(4): 258-268.

, M. C. NOVOA, S. M. CIVITELLA, D. MASON \& A. OVIEDO. 2013. Plantas usadas en medicina popular en la Isla Santiago, Buenos Aires, Argentina. Bol. Latinoam. Caribe Plant Med. Aromat. 12(4): 385-399.

HIERONYMUS, J. 1882. Plantae diaphoricae florae argentinae. Bol. Acad. Cienc. Córdoba 4: 199-598.

HURRELL, J. A., E. A. ULIBARRI, P. M. ARENAS \& M. L. POCHETTINO. 2011a. Plantas de herboristería. L.O.L.A. (Literature of Latin America), Buenos Aires. 242 pp.

—, J. P. PUENTES, F. BUET COSTANTINO, P. M. ARENAS \& M. L. POCHETTINO. 2011 b. Leguminosas medicinales y alimenticias utilizadas en la conurbación Buenos Aires-La Plata, Argentina. Bol. Latinoam. Caribe Plant. Med. Aromat. 10(5): 443-445.

JOHANSEN, D. A. 1940. Plant microtechnique. McGrawHill Book Company, New York.

KORWAR, P. G., A. K. BEKNAL, B. S. PATIL, M. A. HALKAI, U. KULKARNI, R. C. HARIPRASANNA \& S. R. SOODAM. 2010. A study on phytochemical investigation of Drymaria quercifolia Linn rhizome. Int. J. Pharm. Sci. Res. (IJPSR) 1(12): 148-158.

KUTSCHKER, A., H. MENOYO \& V. HECHEM. 2002. Plantas medicinales de uso popular en comunidades del oeste del Chubut. Estación Experimental Agropecuaria de Esquel, Chubut. 139 pp.

LAHITTE, H. B. \& J. A. HURRELL. 1996. Las plantas de la medicina popular de la isla Martín García. Comisión de Investigaciones Científicas de la 
provincia de Buenos Aires (CICPBA). 246 pp.

, K. MEHLTRETER, M. J. BELGRANO, L. S. JANKOWSKI, M. P. HALOUA \& G. CANDA. 1997. Plantas de la costa. L.O.L.A. (Literature of Latin America), Buenos Aires. 200 pp.

—, M. J. BELGRANO, L. S. JANKOWSKI, P. HALOUA \& K. MEHLTRETER. 1998. Plantas medicinales rioplatenses. L.O.L.A. (Literature of Latin America), Buenos Aires. 240 pp.

LERSTEN, N. R. \& J. D. CURTIS. 1987. Internal secretory spaces in Asteraceae. A review and original observations on Conyza canadensis (tribe Astereae). La Cellule 74: 179-196.

- 1988. Secretory reservoirs (ducts) of two kinds in giant ragweed (Ambrosia trifida; Asteraceae). Amer. J. Bot. 75: 1313-1323.

-1989. Foliar oil reservoir anatomy and distribution in Solidago canadensis (Asteraceae: tribe Astereae). Nordic J. Bot. 9: 281-287.

LISCOVSKY, I. J. \& M. T. COSA. 2005. Anatomía comparativa de hoja y tallo en los representantes de Cestreae G. Don (Solanaceae) de Argentina. Gayana Bot. 62(1): 33-43.

- \& N. DOTTORI. 2002. Estudio anatómico de órganos vegetativos en representantes de Datureae (Solanaceae). Bol. Soc. Argent. Bot. 37(3-4): 171180.

LOVISOlO, M. R., A. A. DE MAGistRIS \& N. M. APÓSTOLO. 2003. Anatomía de Ambrosia tenuifolia y Aster squamatus (Asteraceae). XXIX Jornadas Argentinas de Botánica \& XV Reunión anual de la Sociedad Botánica de Chile. Bol. Soc. Argent. Bot. 38 (supl.): 93-94.

LUJÁN, M. C., N. BONZANI, E. FILIPPA \& G. E. BARBOZA. 2004. La "fumarias" (Fumaria spp., Fumariaceae) de uso etnomédico en Argentina y sus adulterantes. Acta Farm. Bonaerense 23(2): 154-164.

MARTÍNEZ CROVETTO, R. 1964. Estudios etnobotánicos I. Nombres de plantas y su utilidad según los indios tobas del este del Chaco. Bonplandia 1: 279-333.

- 1981. Las plantas utilizadas en medicina popular en el noroeste de Corrientes (República Argentina). Miscelanea 69: 1-139.

METCALFE, C. R. 1989. Anomalous structure. In C. R. Metcalfe \& L. Chalk, (dir.). Anatomy of the Dicotyledons Vol. 2: 53-63. Clarendon Press, Oxford.

\& L. CHALK. 1950. Anatomy of the Dicotyledons: leaves, stem, and wood in relation to taxonomy with notes on economic uses. Vol. 1, 2. Clarendon Press, Oxford. $1500 \mathrm{pp}$.

- 1979. Anatomy of the Dicotyledons. Vol. 1. Clarendon Press, Oxford. 276 pp.

MONTI, C., M. C. NOVOA \& C. E. VIZCAÍNO. 2003. Anatomía y etnobotánica de dos especies de
Boraginaceae de la provincia pampeana (Argentina) usadas en la medicina popular. Acta Farm. Bonaerense 22(3): 197-201.

NOVOA, M. C., M. N. COLARES \& A. M. ARAMBARRI. 2012. Anatomy of monocotyledons: stems and rhizomes of land herbs used as medicinal in the Río de La Plata area (Argentina). Bonplandia 21(2): 53-61.

PLOS, A., G. SANCHO \& L. IHARLEGUI. 2011. Secretory structures of leaves of Ophryosporus Meyen (Asteraceae, Eupatorieae), a genus with medicinal properties. J. Torrey Bot. Soc. 138(4): 391-9.

POCCHETINO, M. L., M. R. MARTÍNEZ, B. ITTEN \& M. ZUCARO. 1997. Las plantas medicinales como recurso terapéutico en una población urbana: estudio etnobotánico en Hernández (Pdo. La Plata, Prov. Buenos Aires, Argentina). Parodiana 10(1-2): 141-152.

RAPOPORT, E. H., A. MARZOCCA \& B. S. DRAUSAL. 2009. Malezas comestibles del Cono Sur y otras partes del planeta. INTA, pp. 10-20.

RATERA, E. L. \& M. O. RATERA. 1980. Plantas de la flora argentina empleadas en medicina popular. Ed. Hemisferio Sur, Buenos Aires.

ROIG, F. A. 2002. Flora medicinal mendocina. Las plantas medicinales y aromáticas de la provincia de Mendoza (Argentina). Ed. Universidad Nacional de Cuyo (EDIUNC), Red de Editoriales de Universidades Nacionales (REUN). Mendoza. 302 pp.

RONDINA, R. V. D., A. L. BANDONI \& J. D. COUSIO. 2008. Especies medicinales argentinas con potencial actividad analgésica. Dominguezia 24(1): 47-69.

RUZIN, S. E. 1999. Plant microtechnique and microscopy. University Press, Oxford. 323 pp.

SANTOS, J. B. \& J. P. CURY. 2011. Picão-preto: uma planta daninha especial em solos tropicais. Black Jack: a special weed in tropical soils. Planta Danhina 29: 1159-1172.

SAWCHUK KOBALCHUK, B. 2006. Catálogo españolportugués sobre las utilidades de las plantas medicinales. Estación Exp. Agropec. Cerro Azul INTA, Misiones Miscelánea 55, 116 pp.

SCARPA, G. F. \& R. CAMPOS NAVARRO. 2011. Plantas empleadas contra el "empacho" en la Argentina: análisis botánico y compilación desde el siglo XVIII hasta el presente. XXXIII Jornadas Argentinas de Botánica (resúmen). Bol. Soc. Argent. Bot. 46 (supl.): 141-142.

SELVI, F. \& M. BIGAZZI. 2001. Leaf surface and anatomy in Boraginaceae tribe Boragineae with respect to ecology and taxonomy. Flora 196: 269285.

SIMON, L. E. 1987. Morfología, distribución y valor diagnóstico de los pelos glandulares en especies de Chenopodium L. (Chenopodiaceae). Notas del Museo de La Plata 21(99): 99-110. 
SIMON, P., L. KATINAS \& A. M. ARAMBARRI. 2002. Secretory structures in Tagetes minuta (Asteraceae, Helenieae). Bol. Soc. Argent. Bot. 37(3-4): 181-191.

SORARÚ S. B. \& A. L. BANDONI. 1978. Plantas de la medicina popular argentina. Ed. Albatros, Buenos Aires. 153 pp.

STEIBEL, P. 1997. Nombres y usos de las plantas aplicadas por los Indios Ranqueles de La Pampa (Argentina). Rev. Agron. U.N. La Pampa 9 (2): $1-38$.

STIEFKENS, L., M. HADID, A. PÉREZ, N. DOTTORI \& M. T. COSA. 2010. Anatomía vegetative en tres especies de Salpichroa (Solanaceae). X Simposio Argentino y XIII Simposio Latinoamericano de Farmacobotánica. Libro de resúmenes, p. 77. Facultad de Ciencias Químicas, IMBIVCONICET, Universidad Nacional de Córdoba.

THIERS, B. 2011. Index Herbariorum: A global directory of public herbaria and associated staff, New York Botanical Garden's Virtual Herbarium. http:// sweetgum.nybg.org/ih/ consulted: 06-072012.

TOURSARKISSIAN, M. 1980. Plantas medicinales de la Argentina. Sus nombres botánicos vulgares, usos y distribución geográfica. Ed. Hemisferio Sur, Buenos Aires. 168 pp.

YAGUEDDÚ,C., V.COMPARATORE\& G.PAOLETTI. 2009. Identification of six Papilionaceae species by epidermal characteristics: microanalysis of hand-composed mixtures. Bol. Soc. Argent. Bot. 44(3-4): 305-315.

ZULOAGA, F. O., O. MORRONE\& M. J. BELGRANO. 2008. Catálogo de las plantas vasculares del Cono Sur (Argentina, Sur de Brasil, Chile, Paraguay y Uruguay). I. Monogr. Syst. Bot. Missouri Bot. Gard. 107: 983 pp. http://www.darwin.edu.ar/ consultado: 06-07-2012.

Original recibido el 7 de junio de 2013; aceptado el 14 de agosto de 2013. 
Apéndice 1. Familias, especies estudiadas y uso de los tallos solos, tallo o brotes con hojas, parte aérea o planta entera donde quedarían incluidos los tallos.

AMARANTHACEAE. Alternanthera pungens. Planta entera: digestiva, hepática, diurética, laxante suave, sífilis y enfermedades cutáneas (1-9). Brotes tiernos cocidos: comestibles (10). ASTERACEAE. Achirocline satureoides. Planta: adelgazante (11). Tallos con hojas: digestivo, antiespasmódico, emenagogo; expectorante, sedante y antiflogístico $(6,8,12-15)$. Ramas secas: repelente de polillas (16). Acmella decumbens. Planta: pectoral, analgésico de encías $(3,17,18)$. Tallo (en su parte basal): bactericida y antiviral (19). Ambrosia tenuifolia. Planta: analgésico muscular, cefalálgica (11, 20-22). Bidens pilosa. Planta: antiasmática $(3,20)$; diurética, hipoglucemiante. Tallos: diuréticos, ictericia, halitosis. Tallos con hojas: emenagogo y protector de la mucosa gástrica (6). Tallos tiernos y hojas comestibles (10). Conyza bonariensis. Planta: antirreumática, diurética, úlceras gástricas y enfermedades venéreas; uso externo desinfectante de granos y heridas $(3,11,16,20,23)$. Tallos con hojas: antiulcerosos $(6,8,18$, 20, 24). Galinsoga parviflora. Parte aérea: antiescorbútica y vulneraria (13, 18, 24, 25). Gamochaeta coarctata. Planta: antivariólica, antisarampionosa y antivaricélica $(3,11,20,24)$; uso externo analgésica, vulneraria $(3,8,11,20,24)$. Mikania micrantha. Planta: dolores musculares y reumáticos (11); antitusiva y expectorante (26). Pluchea sagittalis. Tallos tiernos: hepáticos, digestivos, acidez estomacal, tónico, febrífugo; uso externo vulnerario, antiséptico para erupciones cutáneas $(1,8,9,13,15,16,27-30)$. Xanthium spinosum. Planta: febrífuga, digestiva, vías urinarias, diurética (7, 15); uso externo antiséptico en erupciones cutáneas y dolores de cabeza $(1,2,16,22)$. BORAGINACEAE: Borago officinalis. Parte aérea: antiasmática, antirreumática, refrescante, diurética, emenagoga, pectoral y sudorífica $(11,16)$. Tallos tiernos con hojas, comestibles (10). Echium plantagineum. Tallo con hojas: diurético, emoliente y diaforético (3, 11, 13, 24, 25, 31); analgésico (22); adulterante de B. officinalis (31). BRASSICACEAE. Lepidium bonariense. Tallos: afecciones renales (32). Planta: activa circulación (11). Lepidium didymum. Planta: expectorante $(1,4,7)$; tos convulsa, hepática, depurativa, calmante, digestiva $(2,6,11,20)$; analgésica, migrañas, odontalgia, náuseas, musculares $(8,11,20,22)$. Raphanus sativus. Planta: aperitiva, hepática, analgésica para dolores artritis, pulmón, riñones (3). CACTACEAE. Opuntia aurantiaca. Mucílago: tos $(8,11,20)$. O ficus-indica. Mucílago: tos, bronquitis, cáncer (2). Cladodio: antitusivo, hepático y renal (24); antirreumático (25). CAPPARACEAE. Tarenaya hassleriana. Planta: cáustica y rubefaciente, digestiva y antiescorbútica $(3,17,25)$. CHENOPODIACEAE. Dysphania ambrosioides. Empleo cuidadoso es tóxica $(8,33)$. Parte aérea: gastrointestinal $(6,33)$; analgésica estomacal $(22)$; antihemorroidal $(3,20)$; antiinflamatoria, antimicrobiana, insecticida carcinogénica $(5,16)$. D. retusa. Los mismos usos que D. ambrosioides (3). EUPHORBIACEAE: Euphorbia serpens. Planta entera: diurética, emenagoga, febrífuga (34); purgante (3). Látex: uso externo antiherpético y callicida (1-3, 6, 7, 11, 24, 35). FABACEAE: Medicago polymorpha. Brotes tiernos con hojas: adelgazante (11). Trifolium repens. Brotes hojosos: tónico, depurativo, antirreumático, antisifilítico y vulnerario; uso externo cicatrizante llagas y granos $(3,16)$. FUMARIACEAE: Fumaria capreolata. Planta: diurética, laxante, depurativa, tónica, sedante, hipotensora $(3,11,24,25,35)$; uso externo para curar eczemas, dermatosis y exantemas (36). GERANIACEAE: Geranium molle. Planta: febrífuga, galactógena, hepática, antitísica, antihidrópica, astringente, vulneraria (3). G. robertianum. Los mismos usos (11). LAMIACEAE: Marrubium vulgare. Tallos con hojas: tónico estomacal, colerético, antiespasmódico, febrífugo (23). Planta: digestiva; uso externo desinfectante de heridas $(5,11,25)$. ONAGRACEAE: Oenothera affinis. Planta: desinfectante de heridas (3, 11, 25). PHYLLANTHACEAE: Phyllanthus niruri. Planta: disuelve cálculos renales (3, $8,12,15,25,32)$; antidisentérica, antidiarreica, diurética, antidiabética, astringente, antihidrópica, gota, antirreumática $(3,6,16,25)$. Tallos: antiparasitarios (24). PORTULACACEAE: Portulaca oleracea. Parte aérea: facilita la dentición $(11,20)$; purgante, refrescante, diurético, vermífugo, afrodisíaco, colerético, antiescorbútico $(8,23,24,37)$; comestible (10). RANUNCULACEAE: Ranunculus muricatus. Especie tóxica $(25,38)$. Planta: diurética $(3,11)$. SOLANACEAE: Salpichroa origanifolia. Parte aérea: narcótica $(3,13,23)$; antiinflamatoria en uso externo, enfermedades de la piel y sabañones (39). Planta: el zumo en lavajes para evitar la caída del cabello (3). URTICACEAE: Parietaria debilis. Planta: refrescante, estomacal, diurética, febrífuga $(11,20,25)$; analgésica (22); uso externo cataplasmas para tumores 
dolorosos (25). Urtica urens. Planta: hemostática, contra anemia, hemorroides y afecciones de garganta (4, 5). VERBENACEAE: Verbena litoralis: Planta: antifebril y antidiarreica (6); hepática, digestiva (8, 11, 13, 25, 35). $\boldsymbol{V}$. montevidensis: las mismas aplicaciones que la especie anterior (11).

(1)Sorarú \& Bandoni (1978); (2) Pocchetino \& al. (1997); (3) Lahitte \& al. (1998); (4) Barboza \& al. (2001); (5) Kutschker \& al. (2002); (6) Alonso \& Desmarchelier (2005); (7) Carrizo \& al. (2005); (8) Sawchuk Kobalchuk (2006); (9) Scarpa \& Campos Navarro (2011); (10) Rapoport \& al. (2009); (11) Lahitte \& Hurrell (1996); (12) Martínez Crovetto (1964); (13)Toursarkissian (1980); (14) Gattuso \& Gattuso (1998); (15) Chifa \& Ricciardi (2001); (16) Hurrell \& al. (2011a); (17) Lahitte \& al. (1997); (18) Freire \& Urtubey (2000b); (19) Steibel (1997); (20) Martínez Crovetto (1981); (21) Freire \& Urtubey (2000a); (22) Rondina \& al. (2008); (23) Roig (2002); (24) Barboza \& al. (2006); (25) Hieronymus (1882); (26) Colares (2011); (27) Cabrera (1963); (28) Alonso (1998); (29) Freire \& Urtubey (1999); (30) Cambi \& al. (2006); (31) Monti \& al. (2003); (32) Amat \& Yajía (1991); (33) Simón (1987); (34) Hernández (2010); (35) Ratera \& Ratera (1980); (36) Luján \& al. (2004); (37) Figueroa \& al. (2011); (38) Domínguez (1928); (39) Boeris \& al. (2004). 